\title{
Effect of biodiesel on the development of split injection characteristics
}

The paper presents the experimental test results of a common rail injection system operating with biodiesel and the diesel fuel. The three fuel split injection strategies were implemented to investigate the effects made by biodiesel and a fossil diesel fuel on the history of injector inlet pressure and the injection rate. In addition, the three intervals between split injections and the different injection pressures were used to obtain more information about the studied subjects. The obtained results showed that the peak mass injection rates of the main injection phase were slightly higher when using biodiesel than the respective values measured with the normal diesel fuel. Because the first injection phase activated the fuel pressure fluctuations along the high-pressure line and in front of the injector, the time-span between injections has an impact on the injector inlet pressure and thus the fuel injection rate during the second injection phase. Since the nozzle closes little later for biodiesel, the injector inlet pressure also occurred latter in the cycle.

Key words: split injection, injection rate, common rail injection system, diesel fuel, biodiesel fuel

\section{Introduction}

Fuel split injection characteristics play a significant role in the fuel spray development [1, 2], the fuel-air mixture stratification [3], as well as the ignition delay and the subsequent combustion process $[4,5]$ characteristics of the diesel engine.

Han et al. [6] experimentally investigated the split injection process of fatty acid esters on a common rail injection system. The test results show that the fuel properties caused modest changes in the pressure fluctuation after the end of injection as well in the injection mass. The injection dwell time was also found to influence the injector inlet pressure characteristics at the start of the main injection event and thus the amount of fuel injected during main injection was slightly changed.

Han et al [7] also carried out numerical study on fuel physical properties made effects on the split injection processes of a common rail injection system. In that study a one-dimensional model based on AVL HYDSIM was established to identify the effect of fuel density, viscosity and bulk modulus of compressibility on split injection characteristics. Researchers found that fuel physical properties effects were modest at the pilot injection stage, but more noticeable at the main injection stage.

Park et al. [8] experimentally and theoretically investigated the spray and atomization characteristics of biodiesel fuel. It was found that the peak injection rate increased and advanced, when the injection pressure increased due to initial injection momentum. The injection rate of the soybean oil methyl ester, which has a higher density than diesel fuel, is higher than that of diesel fuel despite its low injection velocity.

Boudy and Seers [9] investigated the impact of physical properties of biodiesel on the injection process in a common rail direct injection system using a single and triple injection strategies. The results showed that fuel density is the main property that affects the injection process, such as total mass injected and pressure wave in the common rail system. While the fuel's viscosity and bulk modulus influenced the injection parameters to a lesser degree of extension.
Wang et al. [10] conducted fuel injection and combustion study by the combination of mass flow rate and heat release rate with single and multiple injection strategies. The test results showed that the fuel injection duration is obviously longer than the injection energizing duration. Split injection strategy revealed complicated interaction among splits with the first injection duration and dwell interval dominating the interaction degree. It was also noted that the interaction also considerably depends on the number of splits.

Despite of considerable number of experimental and numerical studies on the subject, in the technical literature still is a lack of knowledge related with the effects of the intervals between the splits and this is especially important in case of using biodiesel. The purpose of the research was to obtain a deeper knowledge about the impact of the widely differing properties of biodiesel on the main injection parameters such as the fuel injection rate and the injector inlet pressure for the three split injection strategies under various biodiesel and the diesel fuel injection pressures.

\section{Materials and method}

The fuel injection rates were measured and analysed using an injection rate measuring system based on Bosch method [11].

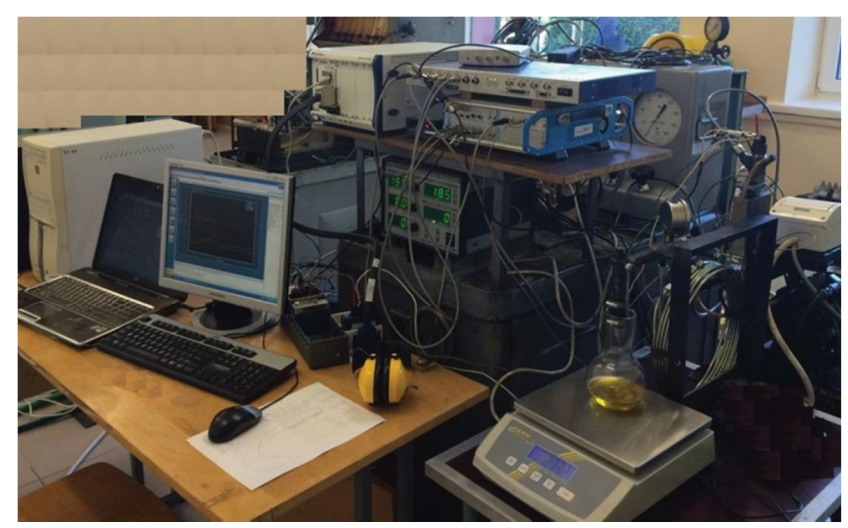

Fig. 1. Test stand used in the experiments 
The experimental setup consists of two parts: the fuel injection system and injection rate measuring system (Fig. 1). The fuel injection system includes an electrically driven high-pressure pump, a rail and an injector. The injector nozzle has 6 holes and the diameter of each hole is 0.24 $\mathrm{mm}$. The NI PXIe 1062Q system with DI Driven D000020 module was used to control the injection process.

The injection rate measuring system consists of the injector mount on which the injector and the pressure sensor are mounted, the measuring and following tube, the orifice plate separating them and the check valve. The injection rate measuring method is based on measuring a dynamic increase in pressure produced by the fuel injection into measuring tube filled with fuel. The shape of the fuel pressure increase correspondents to the injection rate.

The pressure variation in the tube was measured with a piezoelectric pressure sensor type 6052C (Kistler) coupled to the Kistler charge amplifier-module 5064 with an accuracy of $\pm 0.5 \%$ in the pressure range of $0-25.0 \mathrm{MPa}$. The fuel pressure at the injector inlet was measured with a piezoresistive high-pressure Kistler Inc. sensor 4067A2000 and amplified by an amplifier-module 4665. Both amplifier-modules were mounted on the signals conditioning platform-compact 2854A. The injector energizing pulses, fuel injection rate, fuel pressure and back pressure signals were continuously recorded by using an AVL IndiModul 622 data acquisition system.

Table 1. Properties of the tested fuels

\begin{tabular}{|l|c|c|}
\hline Fuel & $\begin{array}{c}\text { Density at } 30^{\circ} \mathrm{C} \\
{\left[\mathrm{kg} / \mathrm{m}^{3}\right]}\end{array}$ & $\begin{array}{c}\text { Kinematic viscosity } \\
\text { at } 40^{\circ} \mathrm{C}\left[\mathrm{mm}^{2} / \mathrm{s}\right]\end{array}$ \\
\hline Diesel fuel & 832.7 & 2.13 \\
\hline RME & 883.6 & 4.44 \\
\hline
\end{tabular}

The fuel studied was rapeseed methyl ester, the split injection characteristics of which were compared with the respective values of a fossil diesel fuel (DF). The main physical properties of the tested fuels are listed in Table 1. Four injection pressures (rail pressures) of 45, 85, 110 and $135 \mathrm{MPa}$ were used for the experimental tests. The back pressure in the tube was adjusted to 4.0 MPa.

The fuel pressure traces over the 100 consecutive injection cycles were recorded and averaged for the analysis. The quantity of the fuel injected (by mass) was determined as a mean value of the 1000 consecutive injection cycles, measured by a precision scale.

Table 2. Test matrix for split injection

\begin{tabular}{|l|c|c|c|}
\hline Injection duration $[\mathrm{ms}]$ & $0.15-1.0$ & $0.5-0.5$ & $1.0-0.15$ \\
\hline Injection interval $[\mathrm{ms}]$ & $0.8 ; 1.0 ; 1.2$ & $0.8 ; 1.0 ; 1.2$ & $2.0 ; 2.15 ; 2.3$ \\
\hline
\end{tabular}

The three groups of the experimental tests with the different injection durations and injection intervals were carried out to reveal the interaction between the splits. The test matrix is shown in Table 2 .

\section{Results and discussion}

Modern diesel engines are equipped with a common rail fuel injection system that can be adapted to implement split injection strategy. In this case, the pressure oscillations in the high-pressure line caused by the first injection affected the subsequent injection process.
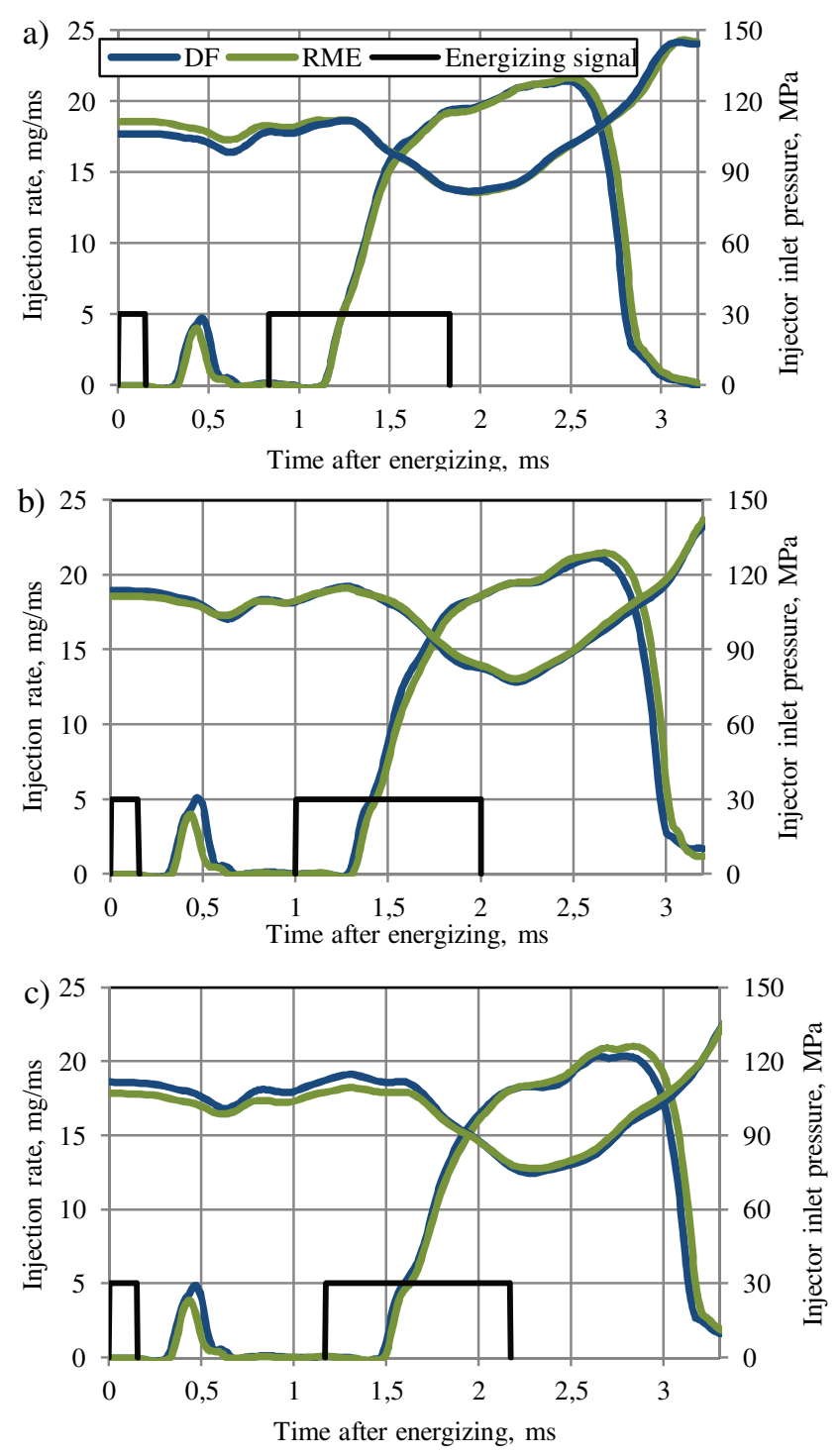

Fig. 2. Effects of pilot injection energizing pulse and split injection interval on the injector inlet pressure fluctuation and the injection rate of the fuels at the injection intervals: $\mathrm{a}-0.8 \mathrm{~ms}, \mathrm{~b}-1.0 \mathrm{~ms}, \mathrm{c}-1.2 \mathrm{~ms}$

Figure 2 shows variations in the fuel mass injection rate and the injector inlet pressure in a time scale during the split injection process, with the duration of $0.15 \mathrm{~ms}$ and 1.0 $\mathrm{ms}$ and a variable interval between injections.

As can be seen in Fig. 2, the short pilot injection pulse causes low-magnitude inlet pressure fluctuation that quickly damps without causing observable influences on the main injection. Higher density of biodiesel fuel causes the reduction of the peak mass injection rate in the pilot stage. While, on the contrary, the peak mass injection rates of the main injection stage were slightly higher when using RME than the respective values measured with the diesel fuel. As can be seen at the end of the main injection, the end of injection takes place slightly earlier in the cycle with diesel fuel. This occurs mainly due to lower viscosity of the diesel fuel. Since the viscosity of biodiesel is higher more time is needed to close the injector due to the viscous forces slowing down the needle movement. While changes in the injection intervals did not have a noticeable effect on the injection characteristics. 

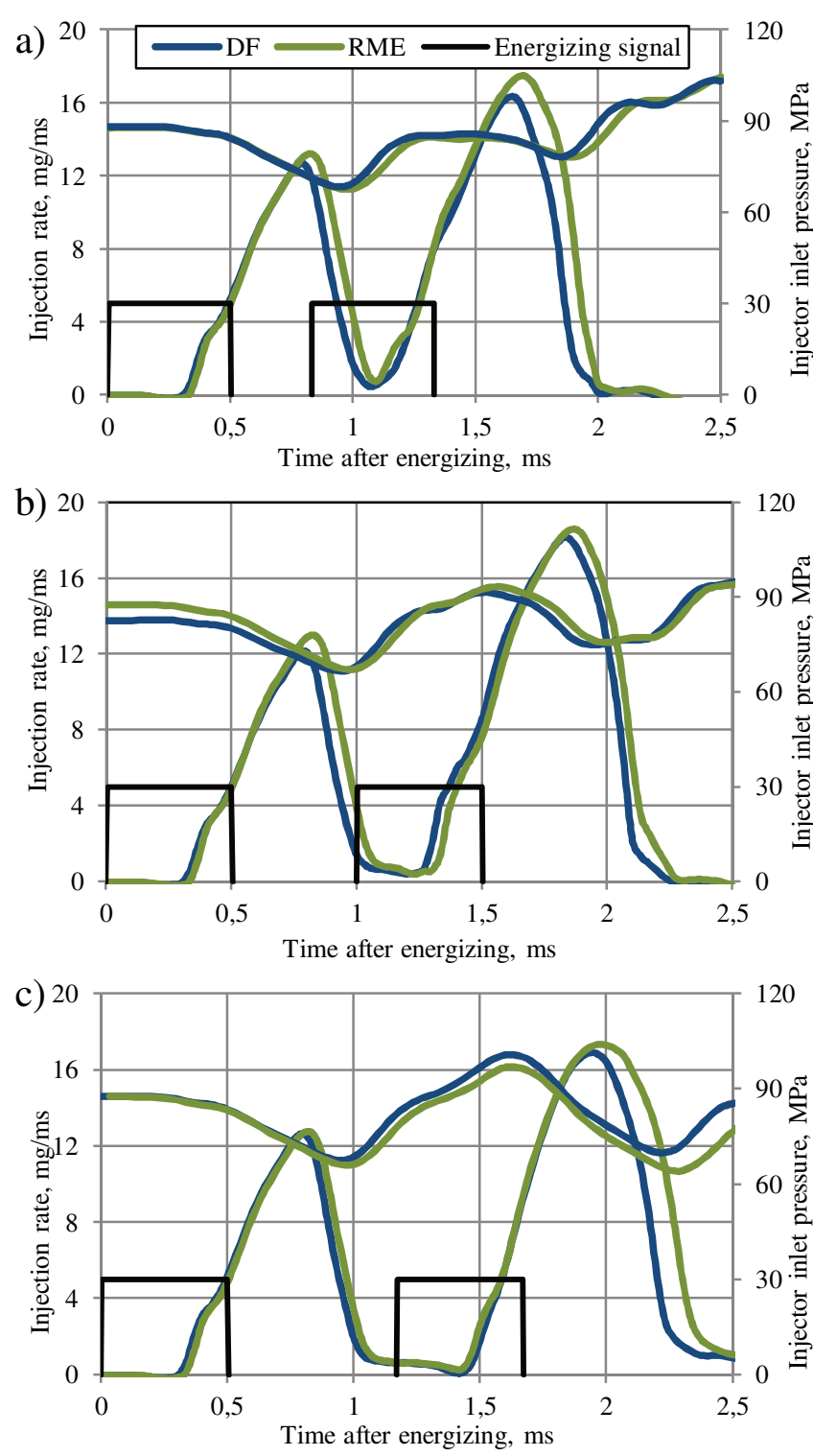

Fig. 3. Effects of fuel types on injector inlet pressure and the injection rate under split injection at the intervals: $\mathrm{a}-0.8 \mathrm{~ms}, \mathrm{~b}-1.0 \mathrm{~ms}, \mathrm{c}-1.2 \mathrm{~ms}$

Figure 3 presents variations in the fuel mass injection rate and the injector inlet pressure during the two-stage injection process for biodiesel and a fossil diesel fuel. The injector energizing duration was equal to $0.5 \mathrm{~ms}$ for each injection event, while the injection intervals were changed for 0.6 (a), 1.0 (b) and $1.2 \mathrm{~ms}$ (c) as can be seen in figure.

As the injection process starts, significant oscillations are observed in the inlet pressure. The first injection causes temporary pressure drops and then subsequently pressure rise caused by the water-hammer effect when the needle moves back into closed position. With an increase in the interval between injections, the fluctuations amplitude of the injector inlet pressure increased correspondingly. At the tested injection intervals of $0.8,1.0$ and $1.2 \mathrm{~ms}$ the respective injector inlet pressure fluctuations amplitudes were equal to 16, 26 and $31 \mathrm{MPa}$. Since after the first injection, the nozzle closes little later for RME than for diesel fuel, the pressure increase is also delayed.

As can be seen in Figure 3, the pressure fluctuations affect the injection rate of the second injection. Due to fuel pressure fluctuations in the high-pressure line evoked by the first injection, the second injection proceeds under the increasing inlet pressure at the injector. For this reason, the fuel injection rate during the second stage of the process was higher than that measured in the first stage of injection. Maximum injection rate is affected by the duration of injection interval between the pulses. Therefore, the maximum injection rate was approximately $32.8 \%$ higher during the second injection than that determined in the first injection stage for both types of the fuels tested with the injection interval of $0.8 \mathrm{~ms}$ between splits.
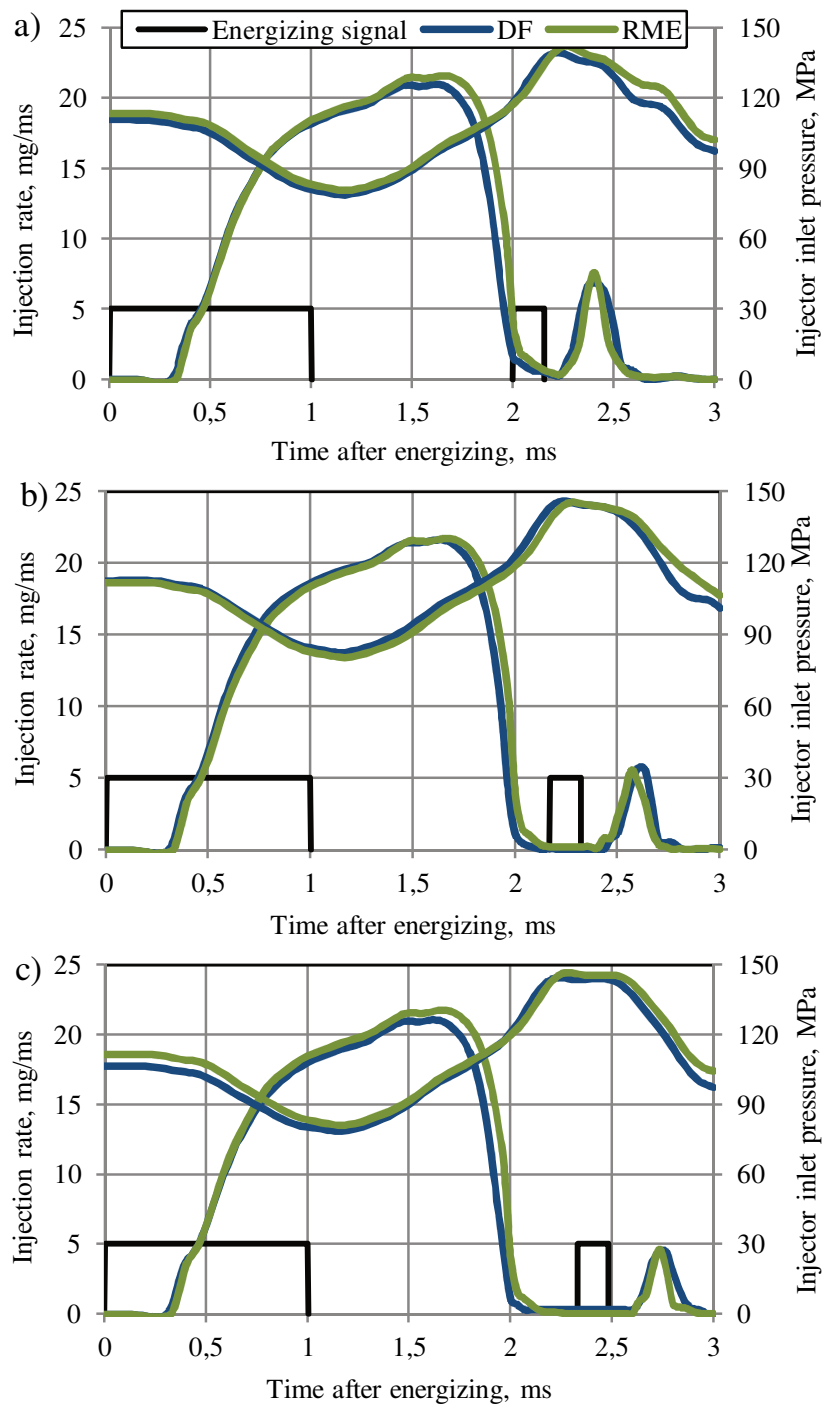

Fig. 4. Effects of fuel types on injector inlet pressure and the injection rate under split injection at the intervals: $a-2.0 \mathrm{~ms}, \mathrm{~b}-2.15 \mathrm{~ms}, \mathrm{c}-2.3 \mathrm{~ms}$

After the injection interval was increased from 0.8 to $1.0 \mathrm{~ms}$ (Fig. 3b), maximum fuel injection rate during the second injection increased by $43.3 \%$ for biodiesel and $49.9 \%$ for the normal diesel fuel. While further increase of the injection interval between splits to value of $1.2 \mathrm{~ms}$ (Fig. $3 \mathrm{c}$ ), maximum injection rate over the second stage increased with a lower intensity - by $36.3 \%$ and $33.6 \%$ for biodiesel and the mineral diesel fuel, respectively. This occurrence can be associated with the fact that the biggest part of the second injection coincided with the reduction 
phase of fuel pressure caused by fluctuation of fuel pressure waves in the high-pressure line activated by the first fuel injection phase.

After the injection interval was increased from 0.8 to $1.0 \mathrm{~ms}$ (Fig. 3b), maximum fuel injection rate during the second injection increased by $43.3 \%$ for biodiesel and $49.9 \%$ for the normal diesel fuel. While further increase of the injection interval between splits to value of $1.2 \mathrm{~ms}$ (Fig. $3 c$ ), maximum injection rate over the second stage increased with a lower intensity - by $36.3 \%$ and $33.6 \%$ for biodiesel and the mineral diesel fuel, respectively. This occurrence can be associated with the fact that the biggest part of the second injection coincided with the reduction phase of fuel pressure caused by fluctuation of fuel pressure waves in the high-pressure line activated by the first fuel injection phase.

Figure 4 presents the history of fuel mass injection rate and the injector inlet pressure during the main injection and post injection events for biodiesel and a fossil diesel fuel for the various injection intervals of $2.0,2.15$ and $2.3 \mathrm{~ms}$. As can be seen in figure, the fuel pressure fluctuations in the high-pressure line have noticeable influence on the shape of a very small time-span characteristic following after the main injection process. The post-injection started just after the fuel pressure at the injector reached the maximum value of about $140 \mathrm{MPa}$, therefore the fuel-mass injection rate was of the biggest values for both injections of biodiesel and the mineral diesel fuel at the injection interval between pulses of $2.0 \mathrm{~ms}$ (Fig. 4a).

As the interval between the injections increased, the maximum injection rate of the second injection gradually decreased because during this phase of process the fuel pressure in the high-pressure line progressively decreased with regard to its maximum value. For this reason, during the second injection the maximum value of injection rate decreased by $26.7 \%$ for biodiesel and $18.8 \%$ for the diesel fuel at the $2.15 \mathrm{~ms}$ interval between injections (Fig. 4b). The interval between injections increased to $2.3 \mathrm{~ms}$, the maximum injection rate additionally reduced by $19 \%$ for both fuel types. Hence, the maximum injection rate developed during the second injection phase depends on the injector inlet pressure fluctuation phase at that instance when the process occurs, i.e. whether the fuel line-pressure increases or decreases at the considered moment.

Figure 5 presents the dependencies of fuel mass injected during two-stage injection process for the three fuel injection intervals between splits and the three initial injection pressures. As expected, for both biodiesel and mineral diesel fuels the cycle injection quantities increased with increasing injection pressure. In case with a small pilot injection (Fig. 5a), cycle injection quantity was not noticeably affected by the time interval between pilot and main injection events because the fuel fluctuations after the first injection were negligible.

In case of the fuel split-injection with the two $0.5 \mathrm{~ms}$ injector energizing pulses, the effect of the injection interval on the mass cycle injection quantity was significand as can be seen in Fig. 5b. As show Fig. 3 and Fig. 5, the cycle injected fuel quantity correlate well with the pressure fluctuations at the injector inlet. At an initial injection pressure of $85 \mathrm{MPa}$, the increase in the injection interval from 0.8 to $1 \mathrm{~ms}$ resulted in the amplitude of pressure fluctuations $17.7 \%$ higher. While, at the same time, the cycle injection mass of mineral diesel and biodiesel increased by $19 \%$ and $8.5 \%$ respectively. As the injection interval increased up to $1.2 \mathrm{~ms}$, the amount of fuel-mass injected decreased as did the pressure fluctuations amplitude.
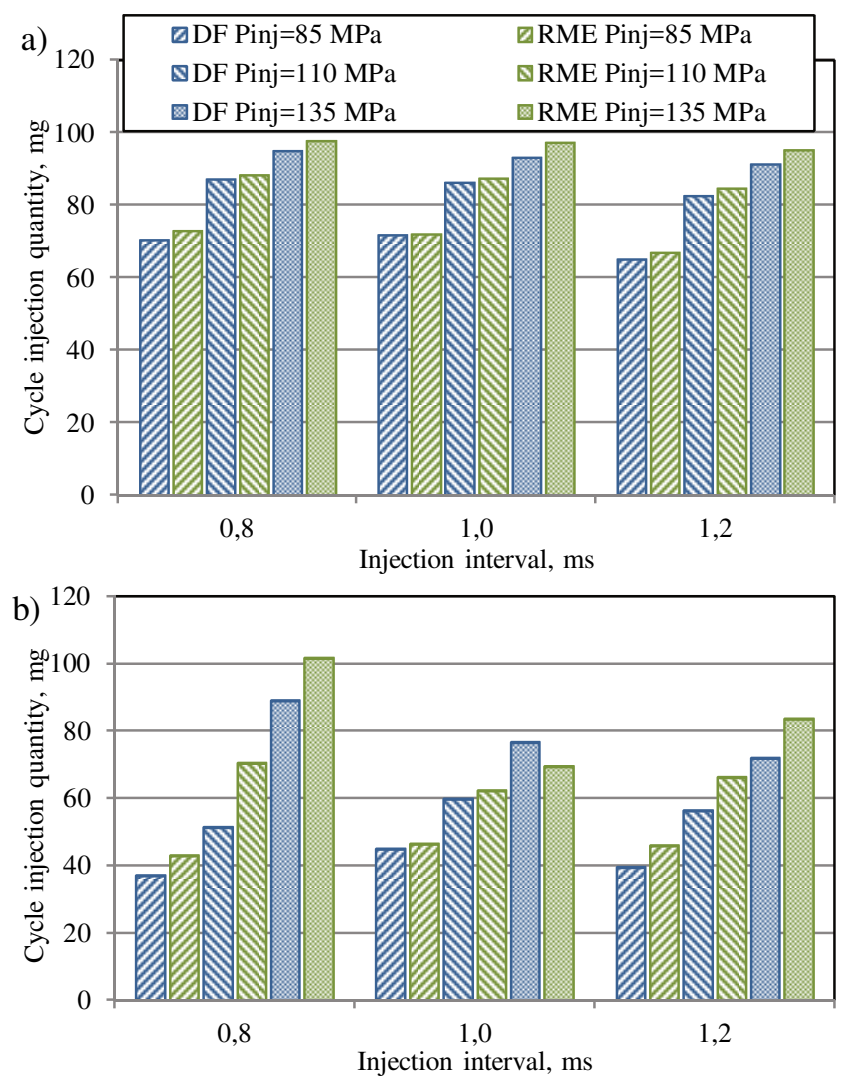

Fig. 5. The effect of injection interval on cycle injection quantity for various injection pressures: a - injector energizing pulses of $0.15-1.0 \mathrm{~ms}$; $\mathrm{b}-$ injector energizing pulses $0.5-0.5 \mathrm{~ms}$

\section{Conclusions}

The three fuel split injection strategies were implemented to investigate the effects made by biodiesel and a fossil diesel fuel on the history of injector inlet pressure and the injection rate. At the same time, the intervals between split injections and the injection pressures were changes to obtain more information about the studied subjects.

The short pilot injection pulse caused low-magnitude inlet pressure fluctuations those quickly have been damped without causing any observable effect on the main injection process. The peak mass injection rates of the main injection phase were slightly higher when using biodiesel than the respective values measured with the normal diesel fuel

Because the first injection phase activated the fuel pressure fluctuations along the high-pressure line and in front of the injector, the time-span between injections has an impact on the injector inlet pressure and thus the fuel injection rate during the second injection phase. Since the nozzle closes little later for biodiesel, the injector inlet pressure also occurred latter in the cycle. 
Acknowledgements

The authors are Thankful to the Company AVL-AST, Graz, Austria, which according the University's Partnership Program, has granted to Power and Transport Machinery Engineering Institute of Vytautas Magnus University the AVL-BOOST program that enhanced the reliability and accuracy of the data obtained.

\section{Nomenclature}

RME rapeseed methyl ester

\section{Bibliography}

[1] LEE, C.S., LEE, K.H., REITZ, R.D., PARK, S.W. Effect of split injection on the macroscopic development and atomization characteristics of a diesel spray injected through a common-rail system. Atomization Spray. 2006, 16(5), 543-562.

[2] WANG, Z.M., XU, H.M., JIANG, C.Z., WYSZYNSKI, M.L. Experimental study on microscopic and macroscopic characteristics of diesel spray with split injection. Fuel. 2016, 174, 140-152.

[3] MA, S.Y., ZHENG, Z.Q., LIU, H.F. et al. Experimental investigation of the effects of diesel injection strategy on gasoline/diesel dual-fuel combustion. Applied Energy. 2013, 109, 202-212.

[4] LIM, J., LEE, S., MIN, K. Combustion modeling of split injection in HSDI diesel engines. Combustion Science and Technology. 2011, 183(2), 180-201.

[5] SARANGI, A.K., GARNER, C.P., MCTAGGART-COWAN, G.P. et al. The effects of split injections on high exhaust gas recirculation low temperature diesel engine combustion. International Journal of Engine Research. 2013, 14(1), 68-79.

[6] HAN, D., DUAN, Y.Z., WANG, C.H. et al. Experimental study of the two-stage injection process of fatty acid esters on a common rail injection system. Fuel. 2016, 163, 214-222.

Prof. Stasys Slavinskas, DSc. - Institute of Power and Transport Machinery Engineering, Faculty of Agricultural Engineering, Vytautas Magnus University.

e-mail: stasys.slavinskas@vdu.lt

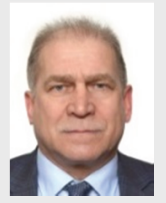

Tomas Mickevičius, DSc. - Institute of Power and Transport Machinery Engineering, Faculty of Agricultural Engineering, Vytautas Magnus Univer-sity. e-mail:tomas.mickevicius@vdu.lt
DF diesel fuel

[7] HAN, D., LI, K., DUAN, Y. et al. Numerical study on fuel physical effects on the split injection processes on a common rail injection system. Energy Conversion and Management. 2017, 134, 47-58.

[8] PARK, S.H., KIM, H.J., SUH, H.K., LEE, CH.S. A study on the fuel injection and atomization characteristics of soybean oil methyl ester (SME). International Journal of Heat and Fluid Flow. 2009, 30(1), 108-116.

[9] BOUDY, F., SEERS, P. Impact of physical properties of biodiesel on the injection process in a common-rail direct injection system. Energy Conversion and Management. 2009, 50, 2905-2912.

[10] WANG, Z., WYSZYNSKI, M.L., XU, H. et al. Fuel injection and combustion study by the combination of mass flow rate and heat release rate with single and multiple injection strategies. Fuel Processing Technology. 2015, 132, 118-132.

[11] BOSCH, W. The fuel rate indicator: a new instrument for display of the characteristic of individual injection. $S A E$ Technical Paper 660749, 1966.

Prof. Gvidonas Labeckas, DSc. - Institute of Power and Transport Machinery Engineering, Faculty of Agricultural Engineering, Vytautas Magnus University.

e-mail: gvidonas.labeckas@vdu.lt

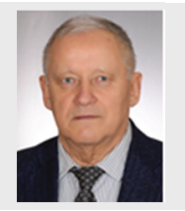

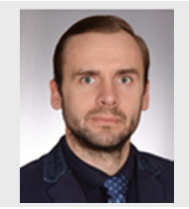

